\title{
Graphophonic Rules Governing English Loanwords in Lontómbá Language
}

\author{
Jean Paul Mola Mbeba \\ Department of English Letters and Civilization, Faculty of Letters and Human Sciences, University of Kinshasa, Kinshasa City, Democratic \\ Republic of Congo
}

Email address:

molajeanpau199@gmail.com

\section{To cite this article:}

Jean Paul Mola Mbeba. Graphophonic Rules Governing English Loanwords in Lontómbá Language. Communication and Linguistics Studies. Vol. 7, No. 1, 2021, pp. 13-20. doi: 10.11648/j.cls.20210701.13

Received: January 29, 2021; Accepted: February 16, 2021; Published: March 12, 2021

\begin{abstract}
The English loanwords entered into Lontómbá language have undergone some adaptation in both spelling and pronunciation. This adaptation needs to be explained in a scientific way. This article analyses 100 English loanwords that have been adapted in Lontómbá language at the graphophonic level so as to find out the rules that govern their adaptation in Lontómbá. To reach this purpose, the based-corpus approach is applied in the analysis of data with a focus on spelling of the original English loanwords and the way they are written and pronounced in Lontómbá language. To put it very clear, the analysis is mainly based on the graphs i.e. how letters are combined to produce one sound in English, and how the same letters are adapted in Lontómbá through the process of epenthesis. In this vein, one can understand that this article attempts to answer the question "are there any rules that govern the change in the spelling of graphs of English loanwords in Lontómbá language?" The analysis of data led to the following results: (1) no English word that enters Lontómbá language keeps its original form. That is to say, English words are adapted in Lontómbá by changing the spelling and pronunciation. (2) Each English loanword entering Lontómbá language must have a vowel grapheme ending by the following sub-rules. (3) Digraphs and trigraphs of English words are eliminated by the process of epenthesis. (4) An English loanword adapted in Lontómbá should not contain the graphemes $\mathrm{r}$ and c (5) An English loanword adapted in Lontómbá should not contain digraph vowels and digraph consonants. (6) English vowel graphemes are also adapted in Lontómbá language according to the way they are pronounced in English. (7) The consonant grapheme in English words c, g, and d that enter Lontómbá language are adapted by changing c into $\mathrm{k}$ or $\mathrm{s}$, g into $\mathrm{k}$, and $\mathrm{d}$ into $\mathrm{t}$.
\end{abstract}

Keywords: Epenthesis, Graph, Loanwords, Graphophonic Rules, Lontómbá, and Borrowing

\section{Introduction}

The contact between the Protestant Missionaries (speaking English) and Bikoro people (speaking Lontómbá) has been the opportunity for Lontómbá speaker to borrow words from the English language. This fact is a sociolinguistic phenomenon known as borrowing. English words, being difficult to pronounce by Bikoro people, were subject to adaptation so as to fit the phonological system of Lontómbá language. Therefore, the English words borrowed in Lontómbá language have changed their spelling and pronunciation. Up to this moment there does not exist any scientific explanation about the graphophonic change of the English loanwords in Lontómbá. The problem that leads to conduct this research is the remarkable lack of a reliable scientific explanation of English borrowings in Lontómbá language. Therefore, this paper examines the English loanwords in Lontómbá language with respect to their spelling (especially graphs, diagraphs, and trigraphs) and pronunciation so as to find out the graphophonic rules that govern the adaptation of the English loanwords in Lontómbá.

\section{Background}

Researchers interested in reconstructing the history of languages often use comparative methods. Kastronic [1] explains the comparative methods by saying that "this type of method is necessary for the reconstruction of the presettlement ancestor because traces of the language at this stage are usually rare, if not completely non-existent, all the 
more if the ancestor that is being reconstructed is a spoken vernacular". Lontómbá has been compared other languages on different phenomena. But no scholar has focused on graphophonic rules. For example Lontómbá has been compared to Lomongo as Mamet [2] states that" the major part of Lontómbá vocabulary and grammar has similar rule to those of Lomongo simply because they share life with Bobangi as neighbours, and they were one of the Mongo migrant part".

When two different people speaking different languages meet, some words are borrowed from one language into another. This sociolinguistic phenomenon is called borrowing The term borrowing is defined by Hoffer [3] as "the process of importing linguistic items from one linguistic system into another, a process that occurs any time two cultures are in contact over a period of time". English loanwords have entered Lontómbá language thanks to the contact between Protestant Missionaries (who were speaking English) and Bikoro people (who were speaking Lontómbá). This contact is a normal linguistic phenomenon. Beel and Felder [4] explain it in this way: "this is a linguistic phenomenon that occurs cross linguistically whenever one language interacts with another language, and generally when one word exists in one language but not in the second language. Besset [5] also adds that "language contact usually results in the use of one-item lexical element from a donor language into a recipient language". Bikoro people preferred to borrow some English words. Considering the term borrowing, Mao and Hulden [6] state that "borrowing lexical items from one language to another is a common linguistic phenomenon". Being unable to pronounce the English loanwords correctly, Bikoro people felt obliged to adapt these English loanwords to the phonological system of their language (Lontomba) as Nagy [7] argues that "loanwords may carry sounds, prosodic and phonotactic patterns that are unknown in the borrowing phonology...". This is also affirmed by Kenstowicz [8] in these terms:

When the phonemic and prosodic structures of the two languages do not align then the loan is reshaped to the closest available language alternative measured in terms of the phonological features operative in the recipient language and their location in feature geometric and prosodic structure.

In the same perspective, the English loanwords having graphs (diagraphs or trigraphs) have been altered so as to facilitate their pronunciation. Aktürk-Drake [9] explains that "in the phonological integration of loanwords, the original structure of the donor language can either be preserved (i.e. adopted) as innovations or altered to fit the existing system of the recipient language (i.e. adapted)". Therefore, the English graphs have undergone some adaptation. The English loanwords have been reshaped by the process of epenthesis so as to facilitate their pronunciation.. Akidah [10] writes that "epenthesis refers to the process of inserting a phoneme (either vowel or consonant) in a word to break the consonant cluster system". Repetty [11] says that "an epenthetic vowel is a vowel inserted into a phonological environment to repair a marked or illegal structure". Graphs of English loanwords have undergone some alternation in specific phonological environment. Jaradat [12] confirms that "phonological processes are usually used to represent the way in which certain sounds undergo phonological changes or alternation in specific environments". In the most of cases the epenthesis is applied to facilitate the pronunciation of independent sounds as Diaz [13] argues that "pronunciation cannot be based on letters, but on independent sounds". In his view Gudia [14] states that "loanwords are usually required to conform to the phonological, morphological and syntactic rules/constraints of $L 1$ to the extent that they become integrated into native phonology through a gradual and a complicated process". In the following section, the discussion is about the analysis of English loanword graphemes in Lontómbá. Murray and Watson [15] explain a grapheme in the following terms:

a grapheme can be a single letter or a combination of letters. A single-letter grapheme is called a graph, as in hat; a two-letter grapheme is called a digraph, as in chicken; a three-letter grapheme is called a trigraph, as in bridge; and a four-letter grapheme is called a quadgraph, as in eight. To avoid confusion in the early years, only the term 'grapheme' is used.

\section{Discussion}

The following are the English loanwords that have entered LONTOMBA linguistic system and have been integrated or adapted with changes in the morphology and phonemics.

Table 1. English loanwords that have entered LONTOMBA linguistic system.

\begin{tabular}{lll}
\hline $\mathbf{N}^{\circ}$ & English Words & English loanwords integrated in LONTOMBA \\
\hline 1 & All right & Oleiti \\
2 & Angel & Angelu \\
3 & Mary & Mali \\
4 & Back & Beki \\
5 & Ball & Bale \\
6 & Bank & Banki \\
7 & Bath & Baafu \\
8 & Battery & Bateli \\
9 & Beach & Bichi \\
10 & Bedroom & Batulu \\
11 & Bethlehem & Beteleme \\
12 & Bible & Biblia \\
\hline
\end{tabular}




\begin{tabular}{|c|c|c|}
\hline $\mathbf{N}^{\circ}$ & English Words & English loanwords integrated in LONTOMBA \\
\hline 13 & Bicycle & Bisengeleti \\
\hline 14 & Blanket & Molangiti \\
\hline 15 & Blue & Bulé \\
\hline 16 & Boat & Bwato \\
\hline 17 & Bol & Bola \\
\hline 18 & Book & Buku \\
\hline 19 & Boy & Boi \\
\hline 20 & Break & Bola \\
\hline 21 & Brush & Bolosi \\
\hline 22 & Building & Buludingi \\
\hline 23 & Bureau ( Office) & Bulo \\
\hline 24 & Cassette & Kasete \\
\hline 25 & Cigarette & Singeleti \\
\hline 26 & Coconut & Kokoti \\
\hline 27 & Coffee & Kafé \\
\hline 28 & Cook & Kuku \\
\hline 29 & Corner & Konele \\
\hline 30 & Cow Boy & Koboi \\
\hline 31 & Cup & Коро \\
\hline 32 & Cup baord & Nkoboti \\
\hline 33 & Doctor & Dokotolo \\
\hline 34 & Drum & Dulumu \\
\hline 35 & Drummer & Dulumele \\
\hline 36 & English & Ngelesa \\
\hline 38 & Envelope & Endolope \\
\hline 39 & Fault & Foti \\
\hline 40 & Football & Futubale \\
\hline 41 & Germany & Jamani \\
\hline 42 & Goal & Gole \\
\hline 43 & Goblet & Gobele \\
\hline 44 & Istrael & Isalaeli \\
\hline 45 & Jacket & Jakete \\
\hline 46 & Jerusalem & Yelusalema \\
\hline 47 & Jesus & Yesu \\
\hline 48 & John & Yoane \\
\hline 49 & Keeper & Kempele \\
\hline 50 & Kettle & Ketele \\
\hline 51 & Knife & Kanifi \\
\hline 52 & Lake & Laki \\
\hline 53 & Mammy-Water & Mamiwata \\
\hline 54 & Mango & Mangolo \\
\hline 55 & Mark & Malako \\
\hline 56 & Marriage & Maliasi \\
\hline 57 & Mass & Mesa \\
\hline 58 & Master & Masta \\
\hline 59 & Matress & Mantela \\
\hline 60 & Matthew & Matayo \\
\hline 61 & $\mathrm{Me}$ & $\mathrm{Me}$ \\
\hline 62 & Meeting & Mentingi \\
\hline 63 & Messiah & Masiya \\
\hline 64 & Meter & Metele \\
\hline 65 & Metallic & Metaliki \\
\hline 66 & Milk & Miliki \\
\hline 67 & Miss & Misi \\
\hline 68 & Moccasin & Mokase \\
\hline 69 & Moniment & Monima \\
\hline 70 & Motor Car & Montuka \\
\hline 72 & Music & Mosiki \\
\hline 73 & Music (plural) & Mesiki \\
\hline 74 & My bathe & Mombafu \\
\hline 75 & My Cake & Monkaté \\
\hline 76 & Onion & Onyo \\
\hline 77 & Pan & Pandi \\
\hline 78 & Pants & Mbati \\
\hline 79 & Penalty & Penati \\
\hline 80 & Soup & supu \\
\hline 81 & Peter & Petelo \\
\hline
\end{tabular}




\begin{tabular}{lll}
\hline $\mathbf{N}^{\circ}$ & English Words & English loanwords integrated in LONTOMBA \\
\hline 82 & Petrole & Pitolo \\
83 & Pin & Pindi \\
84 & Point & Mpwin \\
85 & Police & Pulusu \\
86 & Present & Pelesa \\
87 & Guitar & Kitare \\
88 & Radio & Ladio \\
89 & Sandel & Sandale \\
90 & School & Sukulu \\
91 & Shirt & Soti \\
92 & Sock & Soseti \\
93 & Soldier & Soda \\
94 & Sugar & Ukali \\
95 & Sun & Sae \\
96 & Sunday school & Ntande sukulu \\
97 & School & sukulu \\
98 & Tea & Ti \\
99 & Ketch & Kechi \\
100 & Torch & Tolosi \\
\hline
\end{tabular}

The above corpus shows that all English loanwords in Lontómbá have final vowel ending. Let us examine each vowel ending.

\section{Loanwords Ending into - a}

The loanwords end into -a when the English word ends into:

a) an affricate Sound made of a voiced stop bilabial and a liquid or lateral sound

b) an unvoiced stop alveolar $/ \mathrm{t} /$ preceded by the vowel $/ \mathrm{a} /$, and followed by the sound [ə];

c) an unvoiced stop alveolar $/ \mathrm{t} / \mathrm{preceded}$ by a nasal sound;

d) a voiced stop alveolar /d/ preceded by /1/ and followed by the sound [ə] or [3:];

e) a sound $[\mathrm{k}]$ preceded by a vowel that follows the sound [r];

f) a sound $[\mathrm{k}]$ followed by the sound [a:];

g) a nasal sound preceded by the combination of the sounds [al];

h) a fricative sound preceded by the vowel sounds [I] or [ə] that follows the sound [r] or a fricative preceded by the vowel sound [æ] or [I] which follows the sound [1].

i) a triphtong $[\mathrm{aI}$ ] $]$.

j) a sound [1] preceded by a diphthong [ひ॰];

The loanwords ending into $-e$

The loanwords end into -e when the English word ends into:

a) The sound [1] preceded by the vowel sound [ :] or, [ग] or $[\mathrm{t}]$

b) The sounds $[\mathrm{t}]$ and $[\mathrm{p}]$

The sound [ə]

a) The sound $[a:]$ or $[r]$

b) The sound $[u:]$

c) The sound [I]

d) The nasal sound $[n]$ or $[m]$

The sound $[\mathrm{k}]$ proceeded by another sound $[\mathrm{k}]$ followed by the diphthong [eI].

The loanwords ending into $-i$

The loanwords end into -I when the English word

a) contains the sound $[\mathrm{y}]$ b) ends into the sound [k] when the word does not contain the sound $[\mathrm{r}]$;

c) ends into a fricative sound that does not follow the sound [I] which is preceded by the sound [r], and a fricative the sound that immediately does not precede the sound [æ].

d) ends into an affricate sound;

e) ends into [I] which is preceded either by the sound [r] or a nasal sound or not.

f) ends into the sounds [d] or [t] (dental sounds) preceded by the sound [1] or not;

g) ends into the sound [1];

h) ends into the diphthong [כI];

i) ends into the sound [ə] followed by the sound [g];

j) ends into the sound [n] preceded by the sound [I] or [æ] which immediately follows the plosive unvoiced sound.

Loan Words Ending into -o

The loanwords end into -0 when:

a) the English word ends into the sound [u:] or [כひ] or when the sound [כひ] precedes the last sound;

b) the English long vowel sound [a:] or [i:] precedes an unvoiced sound;

c) the English sound [n] or [1] is preceded at the end of the word by the sound [o];

d) the English the sound [p] at the end of the word is preceded by the sound $[\Lambda]$.

Loan Words Ending into - $u$

The loanwords end into $-\mathrm{u}$ when:

a) the English word ends into the sound [1] preceded by the sound [d3] or the sound [u:];

b) the English word ends into the sound [p] preceded by the sound [u:];

c) the English word ends into the sound $[\theta]$ or the sound [ð];

d) the English word ends into the sound [m] preceded by a sound vowel that is preceded by the sound [r];

e) the English word ends into the sound $[\mathrm{k}]$ preceded $[\mathrm{u}]$;

f) The English word ends into the sound [s] preceded [ə] or [i:]

Apart from the vowel ending, the vowel graphemes within 
the loanwords also undergo changes as follows:

a) The vowel grapheme /e/ changes into the vowel grapheme /a/ in Lontómbá when the vowel grapheme /e/ in the English words is preceded by the plosive or fricative sound.

b) When the English word ends into the sound [1] (preceded by the sound [ว] or [ə]), [m] (if [m] is not preceded by the [1]) or [n], the English loanword ends into the grapheme /e/. If the English word ends into the sound [m] that is preceded by the sound [1], the English loanword in Lontómbá ends into the grapheme /a/.

c) The English grapheme $/ y /$ is changed into the grapheme /e/ when $/ y /$ comes after voiced plosive bilabial sound. It is changed into $/ \mathrm{i} /$ when it follows the $/ \mathrm{r} /$ which is changed into $/ 1 /$.

d) The double grapheme /ee/ changes into /e/ English loanwords in LONTOMBA. The following examples illustrate the case.

e) The English grapheme /a/ changes into /e/ in English loanword in LONTOMBA except when /a/ is followed by a nasal sound.

f) When the English word ends into the plosive, fricative or liquid [r] and [1] (when the sound [1] is preceded by the sound [ə]) sounds, the English loanword ends into the grapheme $/ \mathrm{i} /$.

g) The grapheme /ea/ change into the grapheme /o/ (when the grapheme /ea/ represent the sound [ei]) and /i/ (when grapheme /ea/ represent the sound [i].

h) The grapheme /e/ changes into the grapheme /i/ when /e/ comes after a plosive or fricative sound.

i) The grapheme /au/ are replaced by the grapheme /o/ in the English loanwords in Lontómbá.

j) The grapheme $/ \mathrm{u} /$ changes into the $/ \mathrm{o} /$ when the word is singular, but it changes into / $\mathrm{i} /$ when the word becomes plural.

k) The grapheme /i/ that comes after the grapheme $/ \mathrm{r}$ / changes into /ei/ in the loanword in Lontómbá.

1) The grapheme $/ i$ / that precedes the fricative sound changes into /e/ in the loanword in Lontómbá.

m) In the English word the grapheme /eau/ change into /o/ in the English loanword in Lontómbá.

n) In the English word the grapheme /oa/ change into /uo/ in the English loanword in Lontómbá.

o) In the English word the grapheme / ew/ change into the grapheme $/ y o /$ in the English loanword in Lontómbá.

p) In the English the vowel grapheme /e/ that comes after the consonant $/ v /$ changes into the vowel $/ o /$ in the English loanword in Lontómbá, and the consonant $/ v /$ changes into $/ d /$.

q) When the English monosyllabic word ends into zero vowel, and the word contains the sound [d], $[\theta],[u:]$, $[\mho]$, and $[\wedge]$, the English loanword ends into the grapheme $/ u /$.

r) The English vowel grapheme /a/ changes into / $a a /$ in the English loanword in Lontómbá.

s) The English vowel grapheme /e/ changes into $/ a /$ in the English loanword in Lontómbá when it appears between the grapheme $/ \mathrm{b} /$ and $/ \mathrm{d} /$.

t) In the English word the double vowel /oo/ changes into $/ u /$ in the English loanword in Lontómbá.

u) The English vowel grapheme $/ e /$ changes into $/ u /$ in the loanword in Lontómbá when it follows the sound [s].

v) The English vowel grapheme $/ o /$ becomes $/ u /$ in the English loanword in Lontómbá when it comes after the consonant grapheme $/ p /$. In this case, the vowel grapheme $/ u /$ changes other vowels of the same word into $/ u /$.

w) In the English word the vowel grapheme /ou/ representing the sound $[u:]$ change into the vowel grapheme $/ u /$ in the loanword in Lontómbá.

The consonant graphemes within the English loanwords undergo as it is shown below:

a) The English consonant $/ c /$ changes into the Lontómbá consonant $/ l /$, when the grapheme $/ c /$ is followed by neither $/ e /$ the vowel grapheme nor $/ i /$.

b) The English consonant grapheme $/ \mathrm{c} /$ changes into $/ \mathrm{s} /$ in Lontómbá, when it is followed either /e/ by the vowel grapheme or $/ i /$.

c) The English consonant $/ g /$ changes into $/ k /$ when it appears at the beginning of the world.

d) The English consonant grapheme $/ r /$ changes into $/ l /$ in Lontómbá.

e) The English consonant $/ d /$ changes into the grapheme $/ t /$ in Lontómbá

f) The English consonant grapheme $[g]$ changes into the sound $[k]$ in Lontómbá.

g) The double English consonant $/ f f /$ changes into the grapheme $/ f /$ in Lontómbá.

h) The double English consonant grapheme /tt/ changes into $/ t /$ in Lontómbá.

i) The double English consonant $/ s s /$ changes into $/ s /$ in Lontómbá

j) The combination of the consonant $/ t /$ and $/ h /$ changes into $/ f /$ in Lontómbá.

The double English consonant $/ c /$ changes into $/ k /$ in Lontómbá.

\section{Results and Interpretation}

The analysis of the corpus leads to the following results:

1. No English word that enters Lontómbá language keeps its original form. That is to say, English words are adapted in Lontómbá by changing the spelling and pronunciation.

2. Each English loanword entering Lontómbá language must have a vowel grapheme ending by the following sub-rules.

The final vowel grapheme $a$ of the adapted English loanword is governed by the sub-rules below:

a) an affricate Sound made of a voiced stop bilabial and a liquid or lateral sound;

b) an unvoiced stop alveolar [t] preceded by the vowel a, and followed by the sound [o];

c) an unvoiced stop alveolar [t] preceded by a nasal sound;

d) a voiced stop alveolar [d] preceded by [1] and followed by the sound [ə] or [3:]; 
e) a sound $[\mathrm{k}]$ preceded by a vowel that follows the sound $[\mathrm{r}]$

f) a sound $[\mathrm{k}]$ followed by the sound [a:];

g) a nasal sound preceded by the combination of the sounds [al];

h) a fricative sound preceded by the vowel sounds [I] or [ə] that follows the sound [r] or a fricative preceded by the vowel sound [æ] or [I] which follows the sound [1].

i) a triphtong [aIə].

j) a sound [1] preceded by a diphthong [ひə].

The following rules govern the final vowel /e/ in the adaptation of the English loanwords in Lontómbá. The loanwords end into -e when the English word ends into:

a) The sound [1] preceded by the vowel sound [0:] or, [ग] or $[\mathrm{t}]$

b) The sounds $[\mathrm{t}]$ and $[\mathrm{p}]$

c) The sound [ə]

d) The sound [a:] or [r]

e) The sound [u:]

f) The sound [I]

g) The nasal sound [n] or [m]

h) The sound $[\mathrm{k}]$ proceeded by another sound [k] followed by the diphthong [eI].

The rules that govern the final vowel grapheme of the adapted English loanwords in Lontómbá if the English word

a) contains the sound [y]

b) ends into the sound [k] when the word does not contain the sound $[\mathrm{r}$ ];

c) ends into a fricative sound that does not follow the sound [I] which is preceded by the sound [r] , and a fricative the sound that immediately does not precede the sound [æ].

d) ends into an affricate sound;

e) ends into [I] which is preceded either by the sound [r] or a nasal sound or not.

f) ends into the sounds [d] or [t] (dental sounds) preceded by the sound [1] or not;

g) ends into the sound [1];

h) ends into the diphthong [כI];

i) ends into the sound [ə] followed by the sound [g];

j) ends into the sound [n] preceded by the sound [I] or [æ] which immediately follows the plosive unvoiced sound.

The following rules govern the final vowel grapheme /o/ of the adapted English loanword in Lontómbá when the English word ends into

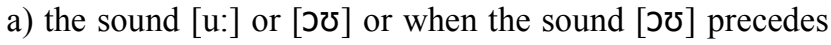
the last sound;

b) the English long vowel sound [a:] or [i:] precedes an unvoiced sound;

c) the English sound [n] or [1] is preceded at the end of the word by the sound [ə];

d) the English the sound [p] at the end of the word is preceded by the sound $[\Lambda]$.

The final vowel grapheme $/ \mathrm{u} /$ is governed by six rules when the English word ends into

a) the sound [1] preceded by the sound [d3] or the sound [u:];

b) the sound [p] preceded by the sound $[\mathrm{u}:]$; c) the sound $[\theta]$ or the sound [ð];

d) the sound $[\mathrm{m}]$ preceded by a sound vowel that is preceded by the sound $[\mathrm{r}]$;

e) the sound $[\mathrm{k}]$ preceded $[\mathrm{u}]$;

f) the sound [s] preceded [ə] or [i:]

1. Digraphs and trigraphs of English words are eliminated by the process of epenthesis.

In Lontómbá language digraphs do not exist except the consonant trigraph grapheme $t s h$ in order to produce the sound [ $\left.\mathrm{t} \int\right]$. Therefore, the English words containing digraphs undergo the process of epenthesis before it is adapted in Lontómbá.

Table 2. English words containing digraphs.

\begin{tabular}{ll}
\hline ENGLISH & LONTÓMBÁ \\
\hline Bedroom & Batulu \\
Bethlehem & Beteleme \\
Bible & Biblia \\
Bicycle & Bisengeleti \\
Blue & Bulé \\
\hline
\end{tabular}

2. An English loanword adapted in Lontómbá should not contain the graphemes $\mathrm{r}$ and $\mathrm{c}$

Table 3. English loanwords adapted in Lontómbá without the graphemes $r$ and $c$.

\begin{tabular}{ll}
\hline ENGLISH & LONTÓMBÁ \\
\hline Cassette & Kasete \\
Cigarette & Singeleti \\
Coconut & Kokoti \\
Coffee & Kafé \\
Cook & Kuku \\
Corner & Konele \\
Cow Boy & Koboi \\
Cup & Kopo \\
Cup baord & Nkoboti \\
\hline
\end{tabular}

3. An English loanword adapted in Lontómbá should not contain digraph vowels and digraph consonants.

Table 4. English loanword adapted in Lontómbá without vowel and consonant diagraphs.

\begin{tabular}{ll}
\hline ENGLISH & LONTÓMBÁ \\
\hline Cassette & Kasete \\
Cigarette & Singeleti \\
Coffee & Kafé \\
\hline
\end{tabular}

4. English vowel graphemes are also adapted in Lontómbá language according to the way they are pronounced in English. That is the sounds of the English words are considered as grapheme in Lontómbá. If the final sound in the English word is consonant or zero vowel sound, the vowel grapheme $a, e, i, o$ and $u$ are used as final vowel grapheme according the sub-rules mentioned above. The following are the adaptation of the English vowel graphemes into Lontómbá. 
Table 5. Adaptation of the English vowel graphemes into Lontómbá.

\begin{tabular}{ll}
\hline English & LONTÓMBÁ \\
\hline$\varnothing$ & $a, e, i, u$ \\
$A$ & $e, a a$ \\
$E$ & $a, i, u$ \\
$I$ & $e i, e$ \\
$O$ & $u$ \\
$U$ & $o$ \\
$Y$ & $e, i$ \\
$A u$ & $o$ \\
$E a$ & $o$ \\
$E a u$ & $o$ \\
$e(w)$ & $(y) o$ \\
$O a$ & $u o$ \\
$O o$ & $u$ \\
$O u$ & $u$ \\
\hline
\end{tabular}

a) If the English word ends into the sound [m] that is preceded by the sound [1], the English loanword in Lontómbá ends into the grapheme a. When an English word does not have a final vowel, and it ends into the sound [1] (preceded by the sound [0] or [ə]), [m] (if [m] is not preceded by the [1]) or [n], the English loanword ends into the grapheme e.

b) The English grapheme y is changed into the grapheme e in Lontómbá when y comes after voiced plosive bilabial sound. It is changed into I when it follows the $r$ which is changed into 1.

c) The English digraph vowel ee changes into $\mathrm{e}$ in Lontómbá.

d) The English grapheme a changes into e in Lontómbá except when a is followed by a nasal sound.

e) When the English word ends into the plosive, fricative or liquid [r] and [1] (when the sound [1] is preceded by the sound [ə]) sounds, the English loanword ends into the $\mathrm{i}$.

f) The diagraph ea changes into the grapheme o (when the digraph ea represents the sound [ei]) and $\mathrm{i}$ (when digraph /ea/ represents the sound [i].

g) The grapheme e changes into the $i$ when e comes after a plosive or fricative sound.

h) The digraph au are replaced by the grapheme o in the English loanwords in Lontómbá.

i) The grapheme $u$ changes into the o when the word is singular, but it changes into $\mathrm{i}$ when the word becomes plural.

j) The grapheme $i$ that comes after the grapheme $r$ changes into ei in the loanword in Lontómbá.

$\mathrm{k}$ ) The grapheme $\mathrm{i}$ that precedes the fricative sound changes into e in the loanword in Lontómbá.

1) In the English word the trigraph eau changes into o in Lontómbá.

m) In the English word the digraph oa changes into wo in the English loanword in Lontómbá.

n) In the English word the digraph ew change into yo in the English loanword in Lontómbá.

o) In the English the vowel grapheme e that comes after the consonant grapheme $\mathrm{v}$ changes into the grapheme $\mathrm{o}$ in the English loanword in Lontómbá, and the consonant grapheme $\mathrm{v}$ changes into $\mathrm{d}$. p) When the English monosyllabic word ends into zero

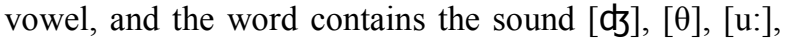
$[\mho]$, and $[\Lambda]$, the English loanword ends into the vowel grapheme $u$.

q) The English vowel grapheme a changes into aa in the English loanword in Lontómbá.

r) The English vowel grapheme e changes into a in the English loanword in Lontómbá when it appears between the grapheme $\mathrm{b}$ and $\mathrm{d}$.

s) In the English word the digraph vowel oo changes into $\mathrm{u}$ in the English loanword in Lontómbá.

t) The English vowel grapheme e changes into $u$ in the loanword in Lontómbá when it follows the sound [s].

u) The English vowel grapheme o becomes u in the English loanword in Lontómbá when it comes after the consonant grapheme $\mathrm{p}$. In this case, the vowel grapheme $\mathrm{u}$ changes other vowels of the same word into $u$.

v) In the English word the vowel grapheme ou representing the sound [u:] change into the vowel grapheme /u/ in the loanword in Lontómbá.

5. The consonant grapheme in English words c, g, and d that enter Lontómbá language are adapted by changing $\mathrm{c}$ into $\mathrm{k}$ or $\mathrm{s}, \mathrm{g}$ into $\mathrm{k}$, and $\mathrm{d}$ into $\mathrm{t}$.

Table 6. The consonant grapheme in English words $c$, g, and d.

\begin{tabular}{ll}
\hline English & LONTÓMBÁ \\
\hline$C$ & $k / s$ \\
$G$ & $k$ \\
$d$ & $t$ \\
\hline
\end{tabular}

1) The English consonant grapheme /c/ changes into the Lontómbá consonant grapheme $\mathrm{k}$ when the grapheme $\mathrm{c}$ is not followed by the vowel grapheme neither e nor $\mathrm{i}$.

2) The English consonant grapheme c changes into $s$ in Lontómbá when it is followed by the vowel grapheme either e or $\mathrm{i}$.

3) The English consonant grapheme g changes into k when it appears at the beginning of the world.

4) The English consonant grapheme d changes into the grapheme $\mathrm{t}$ in Lontómbá.

5) The English consonant grapheme g changes into the grapheme $\mathrm{k}$ in Lontómbá.

The English consonant digraphs are changed into the single grapheme in Lontómbá.

Table 7. The English consonant digraphs changing into single grapheme.

\begin{tabular}{ll}
\hline English & LONTÓMBÁ \\
\hline$F f$ & $F$ \\
$T t$ & $t$ \\
$S s$ & $s$ \\
$T h$ & $f$ \\
$C c$ & $k$ \\
\hline
\end{tabular}

1) The English consonant digraph ff changes into $f$ in Lontómbá.

2) The English consonant digraph tt changes into $t$ in Lontómbá.

3) The English consonant digraph ss changes into $s$ in Lontómbá. 
4) The combination of the consonant grapheme $t$ and $h$ changes into f in Lontómbá.

\section{Conclusion}

This research was conducted because no scientific explanation of the changes in spelling and pronunciation occurring in the English loanwords in Lontómbá is given so far. The aim was to find out the graphophonic rules that govern the changes in the English loanwords in Lontomba so as to provide the community with a reliable explanation the changes mentioned above. To reach this aim a corpus of 100 English loanwords was examined thanks to the based-corpus approach. The analysis revealed the following 7 graphophonic rules:

1. No English word that enters Lontómbá language keeps its original form. That is to say, English words are adapted in Lontómbá by changing the spelling and pronunciation.

2. Each English loanword entering Lontómbá language must have a vowel grapheme ending by the following sub-rules.

3. Digraphs and trigraphs of English words are eliminated by the process of epenthesis.

4. An English loanword adapted in Lontómbá should not contain the graphemes $\mathrm{r}$ and $\mathrm{c}$

5. An English loanword adapted in Lontómbá should not contain digraph vowels and digraph consonants.

6. English vowel graphemes are also adapted in Lontómbá language according to the way they are pronounced in English.

7. The consonant grapheme in English words c, g, and d that enter Lontómbá language are adapted by changing $\mathrm{c}$ into $\mathrm{k}$ or $\mathrm{s}, \mathrm{g}$ into $\mathrm{k}$, and $\mathrm{d}$ into $\mathrm{t}$.

\section{References}

[1] Kastronic, L. (2016). A Comparative Variationist Approach to Morphosyntactic Variation in Hexagonal and Quebec French. Ottawa: Univerityof Ottawa.
[2] Mamet M (1952), La Langue Ntomba, Tervuren, Bruxelles.

[3] Hoffer, B. L. (2002). Language borrowing: Overview in "Intercultural Communication Studies". Trinity University.

[4] Beel, R. And Felder, J. (2013). Phonological Adaptations of English Loanwords in Turkish. Virginia: Liberty University.

[5] Besset, R. M. (2017). Exploring the Phonological Integration of Lone Other-Language Nouns in the Spanish of South Arizone in University of Pennsylvania Working Paper in Linguistics. Arizon: University of Arizona. Vol. 23. Issue 2 pp. 31-39.

[6] Mao, L. J. And Hulden, M. (2016). How Regular is Japanese Loanwords Adaptation? A Computational Study. Colorado: University of Colorado.

[7] Nagy, R. (2010). The Phonological Integration of Loanwords in Dutch. Budapest: Eötvös.

[8] Kenstowicz, M. (2005). The Phonetics and Phonology of Korean Loanword adaptation. Leiden: Leiden University.

[9] Aktürk-Drake, M. (2015). Phonological Adaptation Through Bilingual Borrowing: Comparing Elite Bilinguals and Heritage Bilinguals. Stockholm: Stockholm University.

[10] Akidah, (2013) Phonological And Semantic Change In Language Borrowing: The Case of Arabic words Borrowed into Kiswahili in "International Journal of Education and Research" Vol. 1 No. 4 April.

[11] Repetty, L. (2012). Consonant-Final Loanwords and Epenthetic Vowels in Italian in Catalian Journal of Linguistics. Online.

[12] Jaradat, M. M. (2019). Epenthesis in Jerash Fallaahi Dialect: An Autosegmental Analysis in International Journal of Liberal Arts and Social Sciences. Online.

[13] Diaz, M. A. L. (2014). Scaffolding Students' Phonological Competence through the Integration of Pronunciation Learning Strategies.

[14] Gudia, M. N. A. (2016). Phonological Adaptation of English Loanwords in Ammani Arabic. Manchester: University of Salford.

[15] Murray, B. and Watson, T. (2018). Synthetic Phonics: Key Terms in "Sound Waves" ISBN 9781741353518. 